\title{
O uso do Software Audacity como Mediação Pedagógica no Ensino de História para Educação de Jovens e Adultos
}

\author{
The use of Software Audacity as Pedagogical mediation in the History of Education \\ for Youth and Adult Education
}

\author{
Hudinilson Kendy de Lima Yamaguchi (iD https://orcid.org/0000-0001-6312-3436 \\ Instituto Federal de Educação, Ciência e Tecnologia do Amazonas - IFAM \\ E-mail: hkendy@ifam.edu.br
}

Walcicley Moura Barreto (iD https://orcid.org/0000-0001-6145-8128

Universidade do Estado do Amazonas - UEA

E-mail: wmb.ltd18@uea.edu.br

\section{Resumo}

O uso das Tecnologias da Informação e Comunicação podem auxiliar no processo de ensino e aprendizagem. Nesse sentido, o objetivo deste artigo é descrever a utilização do software Audacity como ferramenta pedagógica de aprendizagem no ensino de História, a partir da produção de arquivos digitais no contexto da Educação de Jovens e Adultos - $\mathrm{EJA}(\mathrm{N}=26)$. O Estudo de Caso foi realizado com alunos de uma escola municipal da rede pública de ensino da cidade de Coari-AM, com a justificativa de incentivar os educandos dessa modalidade de ensino a desenvolverem materiais didáticos em forma de arquivos digitais de áudios através do software, aperfeiçoando assim sua escrita e oralidade. A metodologia é de natureza básica, com caráter descritivo, temporalidade transversal, como instrumento de pesquisa a partir da observação e aplicação de questionário aos alunos com abordagem metodológica de mista. O percurso metodológico iniciou com a criação de roteiros com tema da disciplina de História, seguido pela gravação dos roteiros simulando programas de rádios, finalizando com a apresentação. Os resultados mostraram que o processo de imersão desta ferramenta tecnológica como práticas pedagógicas do ensino estimulou a criatividade e a integração entre os educandos, contribuindo de forma positiva para a aprendizagem e o aperfeiçoamento do processo de ensino dos conceitos de História, de forma dinâmica e prazerosa para os alunos. Assim concluímos que a utilização de ferramentas tecnológicas, como o software Audacity, dinamizam as práticas pedagógicas e apresentam-se como alternativas viáveis para o processo de ensino e aprendizagem.

Palavras-chave: Aprendizagem. Tecnologia. Educação.

\begin{abstract}
The use of Information and Communication Technologies can assist in the teaching and learning process. In this sense, the objective of this article is to describe the use of the Audacity software as a pedagogical learning tool in the teaching of History, based on the production of digital files in the context of Youth and Adult Education - EJA $(\mathrm{N}=26)$. The Case Study was carried out with students from a municipal public school in the city of Coari-AM, with the justification of encouraging students of this type of teaching to develop didactic materials in the form of digital audio files through the software, thus perfecting their writing and orality. The methodology is basic in nature, with a descriptive character, transversal temporality, as a research instrument based on the observation and
\end{abstract}


application of a questionnaire to students with a mixed methodological approach. The methodological path started with the creation of scripts with the theme of History, followed by the recording of the scripts simulating radio programs, ending with the presentation. The results showed that the immersion process of this technological tool as teaching pedagogical practices stimulated creativity and integration among students, contributing positively to the learning and improvement of the teaching process of the concepts of History dynamically and pleasantly to the students. Thus, we conclude that the use of technological tools such as the Audacity software, dynamize pedagogical practices, presenting themselves as viable alternatives for the teaching and learning process.

Keywords: Learning. Technology. Education.

\section{Introdução}

A utilização de diferentes tecnologias como ferramenta transformadora na prática pedagógica é um tema muito discutido na atualidade e vive-se uma explosão de inovações tecnológicas e, quase tudo, gira em torno desta revolução digital. As mudanças tecnológicas, segundo Flores; Ribeiro e Echeverria (2017), estão ocorrendo de maneira rápida e progressiva, propiciando bem-estar, comodidade e entretenimento às pessoas. O desenvolvimento do processo de ensino e aprendizagem também evoluiu, passando das formas tradicionais para as mídias digitais e:

Estes avanços tecnológicos popularizaram o acesso à informação, modificando a maneira como se vive e, consequentemente, a maneira como se aprende. A sociedade, atualmente, está conectada em rede provocando mudanças, e é notório que a aprendizagem não é mais individual, e sim coletiva (RIOS, 2016, p. 240).

O uso das Tecnologias da Informação e Comunicação - TIC, como ferramentas pedagógicas, já é uma realidade para o desenvolvimento interativo do processo de ensino e aprendizagem. Baseando-se nestas premissas, a integração das TIC, na Educação de Jovens e Adultos - EJA, é uma alternativa viável, oportunizando um ambiente incentivador para a realização de atividades de ensino de forma diferenciada, oportunizando novas possibilidades de desenvolvimento intelectual.

Apesar dos alunos da EJA "apresentaram dificuldades de acesso e de navegação, é necessário um esforço maior em prol do trabalho de letramento digital destes alunos, visando o entendimento destas tecnologias" (SANTOS; SOUZA, 2018, p. 4145). É importante o estímulo a estes alunos, pois o uso das tecnologias digitais, é uma possibilidade de aprendizagem. Dias (2018) associa o uso de tecnologia em ambientes escolares à lugares de transformação e inclusão digital.

Nessa perspectiva, o acesso às TIC, como ferramentas pedagógicas empoderam os alunos, que passam a ser protagonistas de sua aprendizagem e, à medida que eles vão participando ativamente de aulas dinâmicas, com a criações de áudios digitais educacionais, eles vencem as dificuldades de ensino, peculiares à EJA, tornando esse processo de ensino e aprendizagem mais dinâmico e atrativo.

Portanto, a partir da análise sobre o uso das TIC para o desenvolvimento do processo de ensino e aprendizagem, pensou-se na temática, que tem como 
objetivo, descrever o uso do software Audacity aplicado ao ensino de História aos alunos da EJA.

\title{
Educação de Jovens e Adultos - EJA
}

Com o intuito de superar a problemática da baixa escolarização e analfabetismo da população brasileira, a EJA surgiu com o objetivo de possibilitar a formação escolar desse público que sempre esteve à margem da sociedade:

\begin{abstract}
Essa modalidade é destinada a jovens e adultos que não tiveram continuidade em seus estudos e para aqueles que não tiveram acesso ao 5 ensino fundamental ou médio na idade apropriada. A Educação de Jovens e Adultos (EJA) é o nome do antigo supletivo. (BRASIL, 2018, p. 3)
\end{abstract}

Esta modalidade de ensino criada para equalizar a defasagem escolar de jovens e adultos, normatizado pela Lei 9.394/96, que institui as Diretrizes e Bases da Educação Nacional, versa em seu artigo 37 que: "A educação de jovens e adultos será destinada àqueles que não tiveram acesso ou oportunidade de estudos no Ensino Fundamental e Médio na idade própria" (BRASIL, 1996), oportunizando à convivência igualitária em uma sociedade que, muitas vezes, marginaliza e exclui os indivíduos não alfabetizados. Freire (1979) relata que uma das funções da educação dirigida a jovens e adultos é humanizar o homem. Outra caracterização dada à este público é que:

São pessoas de diferentes faixas etárias, naturais de diversas regiões e, em sua grande maioria, trabalhadores. Em meio a toda essa diversidade, todos possuem algo em comum: não tiveram a oportunidade de acesso e permanência na escola, seja na infância ou na juventude (VIEIRA, CRUZ, 2019, p. 60).

O perfil do aluno da EJA é descrito por Santos, et al. (2019, p. 468), em sua obra, como: "uns alunos com poder aquisitivo baixo, sem acesso à cultura que precisam trabalhar o dia todo e que dispõem de pouco tempo para se dedicar aos estudos e apresentam necessidades educacionais especiais." Santos (2015) aponta outros problemas encontrados por este aluno: idade avançada, o tempo que estiveram ausentes da escola, a falta de hábito de estudar, de ler, de compreender os conteúdos e o pouco uso da norma culta da língua portuguesa.

Portanto, para Carvalho (2016), a EJA deve estar pautada em uma aprendizagem com autonomia e liberdade de expressão, para que eles não fiquem desestimulados mais uma vez e abandonem novamente a escola. Assim o professor tem papel fundamental, disponibilizando instrumentos educacionais, onde o aluno possa ter domínio e seja protagonista no processo de aprendizagem, para que eles sintam participante de sua própria educação e no:

[...] processo de ensino-aprendizagem através das diferentes formas, que ora procura dar ênfase à figura do professor como detentor do saber, responsável pela transmissão do conhecimento, ora venha destacar o papel do aluno como sujeito aprendiz e construtor de seu próprio conhecimento (LOPES, 2011, p. 11).

Em paralelo, a escola pública deve viabilizar a utilização de recursos tecnológicos, como: computadores, aparelhos multimídia, celulares e data-shows, além de proporcionar a capacitação do docente para ele ministrar aulas proativas, correlacionando-as como temas significativos para os estudantes, dinamizando a 
monotonia das aulas tradicionais e trazer o diálogo como forma de minimizar as dificuldades dos estudantes.

\section{Tecnologias da Informação e Comunicação - TIC}

O uso de tecnologia no âmbito da aprendizagem, a exemplo das TIC como ferramentas pedagógicas, fomentando o processo de ensino e aprendizagem, onde: "[...] a disseminação do uso de tecnologias que são fruto da Revolução Digital, nos diferentes campos científicos, coloca-nos diante de mudanças na cultura, na sociedade, na economia, na educação" (ANDELIERI; ADÓ, 2014, p. 240).

Neste sentido, o ato de ensinar do docente deve passar pelo propósito de estar aberto ao novo, sem refutar o tradicional, estando apto a aprender novos métodos, inserindo práticas docentes e artefatos que ajudem a mediar o processo de ensino e aprendizagem, ao implementar e/ou ampliar o acesso as TIC, pois não são só grandes desafios para às Instituições Educacionais, bem como para os profissionais de educação, que devem buscam melhorar suas práticas pedagógicas, já que:

[...] o maior desafio ainda é universalizar o acesso às TIC para atingir todo o contingente de alunos brasileiros, docentes e estabelecimentos escolares; ampliar a compreensão de que o alicerce conceitual para o uso de tecnologias na educação é a integração das TIC ao currículo, ao ensino e à aprendizagem, numa ótica de transformação da escola e da sala de aula em um espaço de experiência, de formação de cidadãos e de vivência democrática, ampliado pela presença das TIC (ALMEIDA, 2008, p.124).

As TIC estão presentes e empregadas em todas as áreas da sociedade como indústrias, saúde, esporte e lazer, impactando-as positiva ou negativamente, dependendo da forma como se faz uso dela. Igualmente, essas novas tecnologias também estão sendo cada vez mais inseridas na educação, servindo como suporte às práticas pedagógicas que, segundo Nogueira (2014), podem facilitar o processo de aprendizagem, onde o aluno tem acesso a diversos tipos de linguagens da mesma informação, tendo a possibilidade de escolher a que mais se adequa ao seu estilo e aptidão de aprendizagem.

A presença da Cultura Digital - CD, na vida dos alunos, é relatada por Pescador (2010) como um choque de gerações entre os nativos Digitais (alunos com idade inferior à 25 anos) e os Imigrantes Digitais, em que as escolas devem fazer uma confluência entre essas gerações, mediando um diálogo articulado dessas tecnologias com o ambiente escolar.

Ao inseri as TIC como uma ferramenta de apoio às práticas pedagógicas, podemse proporcionar aulas teóricas mais atrativas, pois elas podem ser "um suporte motivador, facilitando o processo de aprendizagem e auxílio no atendimento das necessidades desse aluno, que é influenciado por diferentes mídias e que deve conviver, naturalmente, com todas elas" (SANTOS; AMORIM; MATTA, 2017, p. 140).

\section{O uso do software Audacity no processo de ensino e aprendizagem}

Dentre as TIC, que vêm sendo utilizadas como facilitadoras no processo de ensino e aprendizagem, podemos citar o software Audacity por se tratar de um recurso "que pode ser usado no ambiente educacional para a produção e registro de textos dos alunos em forma de áudio" (SAMPAIO, 2015, p. 11). Este software é uma ferramenta de gravação e edição de áudio livre e disponível gratuitamente para 
download, e sua interface propicia um fácil manuseio, no qual se permite importar e exportar arquivos de áudios em variados formatos.

A edição de áudio é o ponto central deste software, que "[...] constrói, de maneira organizada, a mensagem radiofônica, podendo editar os arquivos digitais de áudio, com a possibilidade de criar e recriar os arquivos sonoros" (VILAÇA; LIMA, 2015, p. 83), podendo também, propiciar aos educandos acesso a vários tipos de linguagens, potencializando seu aprendizado, melhorando sua oralidade e escrita através da elaboração de roteiros para programas de arquivos sonoros digitais e, mesmo que os educandos não tenham acesso à internet, esses arquivos podem ser disponibilizados off-line. (GIOVANI, et al. 2014).

O Audacity é um software livre e gratuito, podendo ser utilizado para fins institucionais, comerciais ou pessoais, "o programa está disponível para Mac, Microsoft Windows, GNU/Linux e outros sistemas operacionais" (GIOVANI, et al. 2014, p. 344). Esse software vem sendo utilizado no contexto acadêmico como ferramenta pedagógica, conforme estudos de Sampaio (2015), Rosa, (2017); Almeida, et al. (2018); Costa e Meneses, (2019) e Braga, et al. (2019), podendo ser adaptado para o ensino de História, de acordo com o objetivo desta pesquisa.

\section{Metodologia}

A pesquisa é de natureza aplicada, pois visa sanar os desafios da EJA, por meio de soluções viáveis aos enfrentamentos que a modalidade de ensino encontra (ANDRADE, 2018). O método utilizado foi o Estudo de Caso, já que não houve nenhuma comparação anterior ao início do referente trabalho; o objetivo da pesquisa é descritivo, com o intuito de conhecer o cenário, frente ao processo de ensino e aprendizagem (GIL, 2018), com abordagem mista e temporalidade transversal, (MALHOTRA, 2019), pois as informações foram catalogadas no espaço temporal de julho à outubro de 2019 (COOPER; SCHINDLER, 2016).

O Roteiro Metodológico, aplicado neste Estudo de Caso proposto foi dividido em 4 (quatro) momentos distintos e complementares, conforme Figura 1: Avaliação Inicial; Desenvolvimento; Prática Pedagógica e Avaliação.

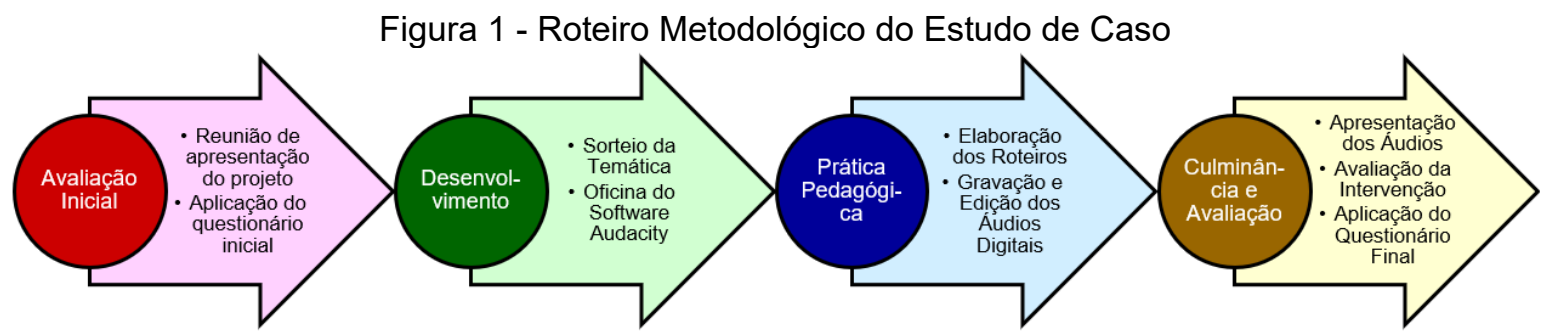

Fonte: Dados Primários (2021)

Os recursos de TIC usados nesta prática pedagógica foram: Celular smartphone para gravação dos áudios digitais; Datashow para a projeção das imagens; Caixa de Som para transmissão dos sons; Computador para edição dos áudios digitais no software Audacity.

O conjunto de ações que fizeram parte da proposta, serviram como componentes educacionais utilizados na apresentação final. Para o desenvolvimento da pesquisa, foram elaborados 8 protocolos de ação e avaliação, distribuídos em 9 aulas 
Resultados Pretendidos da Aprendizagem:

Diagnóstico dos conhecimentos adquiridos após a aplicação da Percurso Metodológico.

Fonte: Dados Primários (2021)

\section{Resultados e Discussão}

Avaliação Inicial: foi realizada a apresentação da proposta de pesquisa para o conjunto de alunos da EJA ( $\mathrm{N}=26)$ de uma escola da rede pública municipal de ensino da cidade de Coari, seguido da aplicação de um questionário impresso, em sala de aula, para diagnosticar o perfil socioeconômico do alunado e o seu nível de conhecimento em informática. Sua aplicação foi importante, pois permitiu traçar o panorama dos alunos do EJA.

A caracterização dos pesquisados nos mostra que os alunos estão em uma faixa etária de 16 a 35 anos, de ambos os sexos, são de baixa renda ( 0 a 3 salários mínimo), este último dado, associa os alunos a uma marginalidade do conhecimento informacional ou excluída digitalmente (NUNES; DIAS; LIMA, 2016). Apesar dos alunos estarem entre as tecnologias digitais, eles não têm familiaridade com elas, necessitando assim de formação para inclusão digital e realizarem suas atividades de forma autônoma.

A partir do levantamento, constatamos também que os alunos do estudo enquadram-se no perfil da realidade brasileira dos alunos da EJA, que no geral, é composto por "jovem estudante com trabalho, ou desempregado, e agrega-se ao curso da EJA com o objetivo de concluir etapas de sua escolaridade para possíveis melhores ofertas no mercado de trabalho" (RIOS, 2018, p.12).

O levantamento revelou que os alunos não conheciam o software Audacity e que $42,3 \%$ dos alunos não possuíam nenhum tipo de conhecimento em informática, estes dados podem ser visualizados na Tabela 1.

Tabela 1 - Caracterização dos alunos do EJA $(\mathrm{N}=26)$

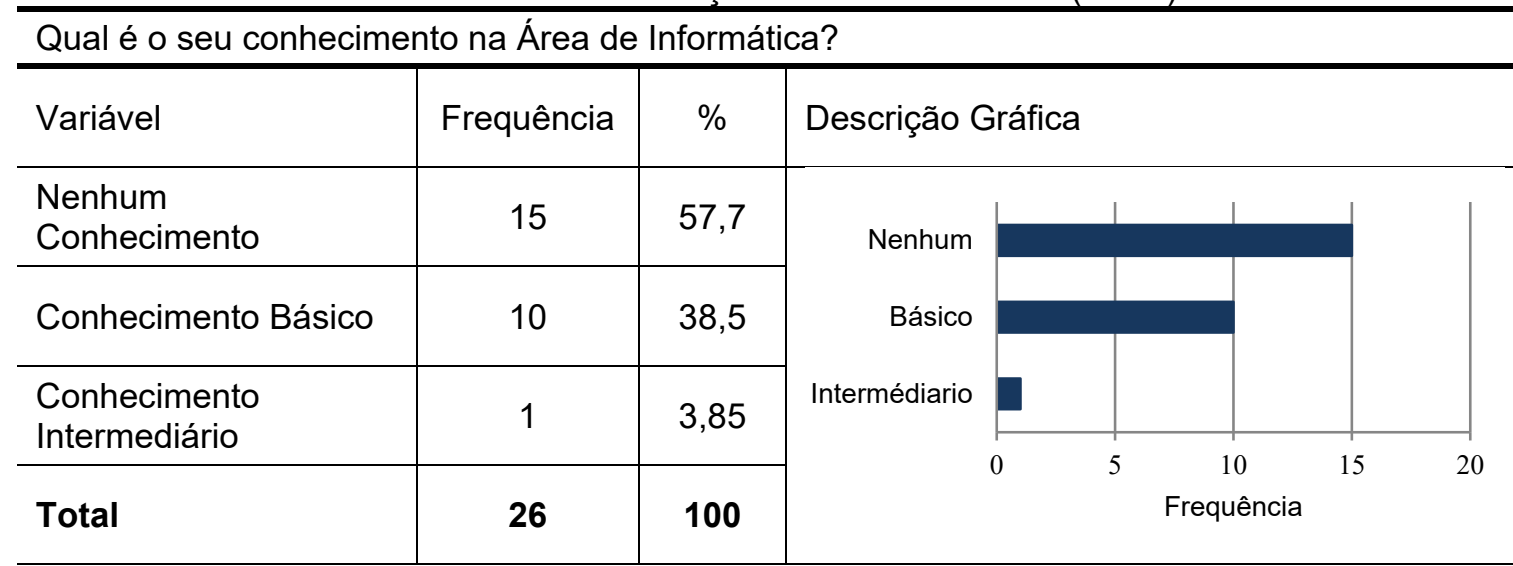

Fonte: Dados Primários, 2021.

Atualmente, vivermos em um mundo globalizado, onde o processo de inclusão digital é caracterizado por Coelho (2011) como uma democratização do acesso às tecnologias da informação, mas ainda existem lacunas de acesso à informação, pois nem sempre este acesso está disponível para os alunos da EJA.

No estudo de Rios (2018), fica evidente que o conhecimento em informática é necessário e de extrema importância para contribuição de um ensino mais dinâmico 
e coerente ao mundo globalizado em que vivemos, pois a informática é uma ferramenta que facilita a formação de cidadãos capazes de verem o mundo por uma vertente digitalizada.

Os estudos de Bocasanta e Wisch (2018) revelam que apesar de parte dos alunos da EJA, assim como o levantamento de nossa pesquisa, não possuírem conhecimento em informática, eles são curiosos e querem aprender, corroborando com Gomes (2017), que relata o interesse dos alunos do EJA, em buscar novos conhecimentos, para ingressar no mercado de trabalho, visando sua independência financeira e melhoria na sua qualidade de vida e de seus familiares.

Outro questionamento feito aos alunos foi como eles avaliavam as dinâmicas das aulas expositivas tradicionais em uma escala: Insuficiente; Regular; Boa; Ótima e Excelente. Representados na Tabela 2.

Tabela 2 - Percepção dos alunos do EJA, quanto a disciplina de História $(\mathrm{N}=26)$

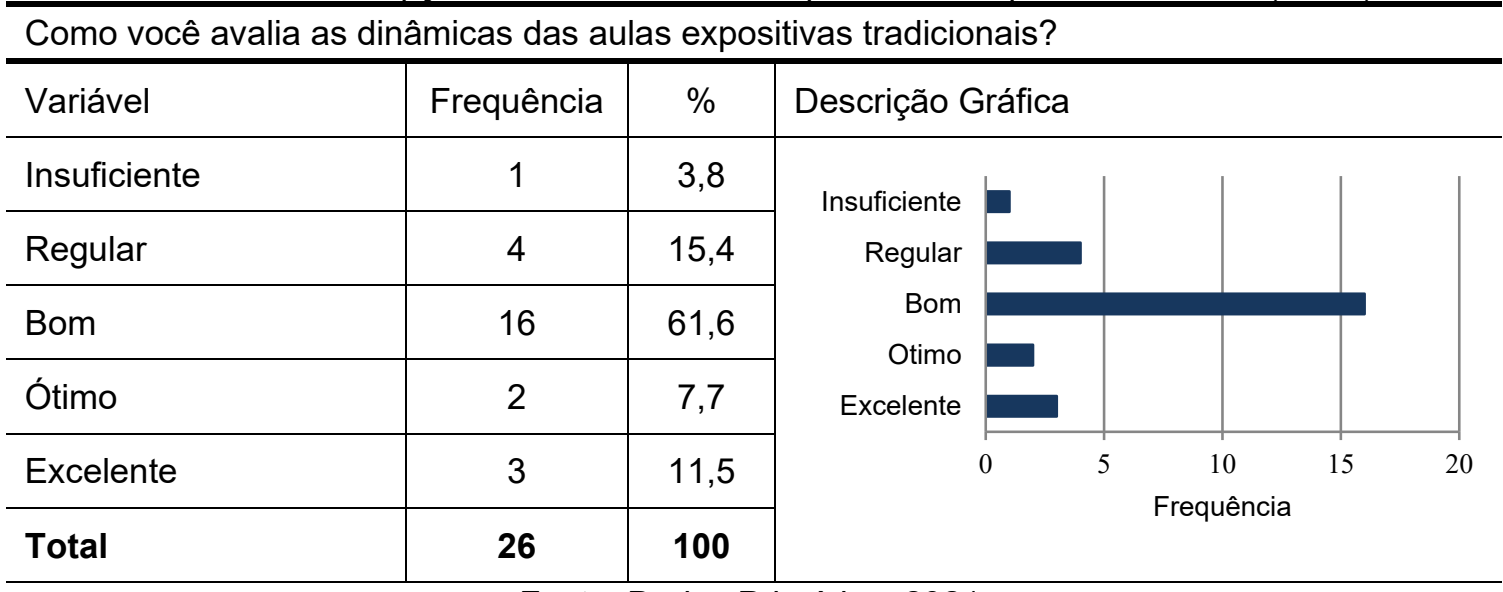

Fonte: Dados Primários, 2021.

O cenário apresentado abre precedentes para a implementação de uma "prática educacional que fomenta a criação de novos desafios e perspectivas para o aprendizado do aluno de forma interativa e colaborativa, transformando a construção dos significados por meio do uso de TIC" (SAID, et al. 2019, p. 5).

O desenvolvimento das atividades iniciou na sala de aula, com a divisão dos grupos de trabalho, por conveniência, com variante máxima de 4 (quatro) integrantes por grupo e o sorteio aleatório dos temas. Em seguida foi apresentado aos alunos a metodologia que foi adotada na apresentação dos áudios sobre a Constituição Brasileira e a ocupação da Amazônia.

Em um outro momento, no laboratório de Informática da escola, foi realizada uma oficina de apresentação do software Audacity e suas ferramentas. Para esta oficina, foi utilizada uma metodologia participativa, estimulando os estudantes a interagirem com o software. Como resultados do processo, podemos observar que o conteúdo foi assimilado de forma mais rápida, pois "o aluno está no centro da atividade e sua aprendizagem é o principal resultado a ser alcançado" (MARQUES; STENTZLER, 2019, p. 198).

A Prática Pedagógica foi desenvolvida na sala de aula, iniciando com uma oficina de orientação sobre a linguagem radiofônica, "que engloba uma série de fatores que ajudam a transmitir a emoção desejada" (FERRARETTO, 2014, p.35), seguindo da produção do roteiro, para gravação dos áudios apresentados na Figura 2. Nesta 
etapa, os grupos de alunos fizeram a seleção dos tópicos, descrevendo o assunto de cada grupo, em seguida, eles escreveram o roteiro proposto, pontuando os principais elementos da Constituição Brasileira ou Ocupação da Amazônia. Por fim, após a revisão do roteiro, foi feita a gravação dos áudios digitais, utilizando os celulares smartphone dos próprios alunos.

Figura 2 - Gravação de áudios digitais

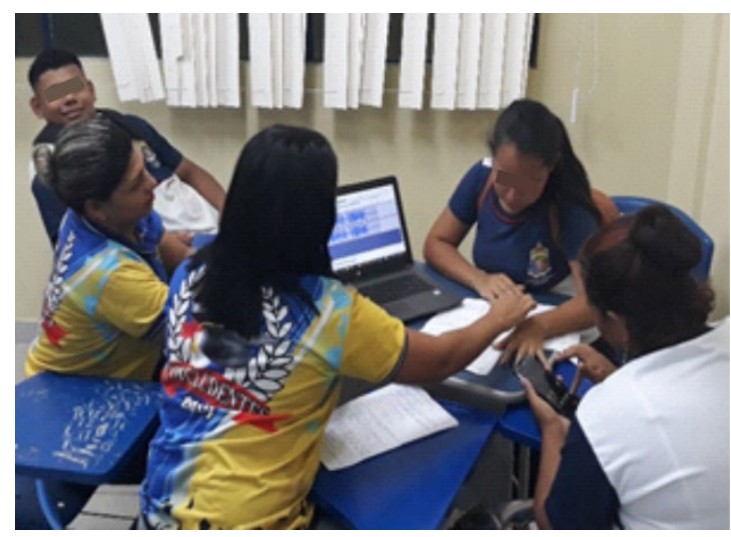

Fonte: Dados Primários, 2021.
Figura 3 - Edição dos áudios no Software Audacity

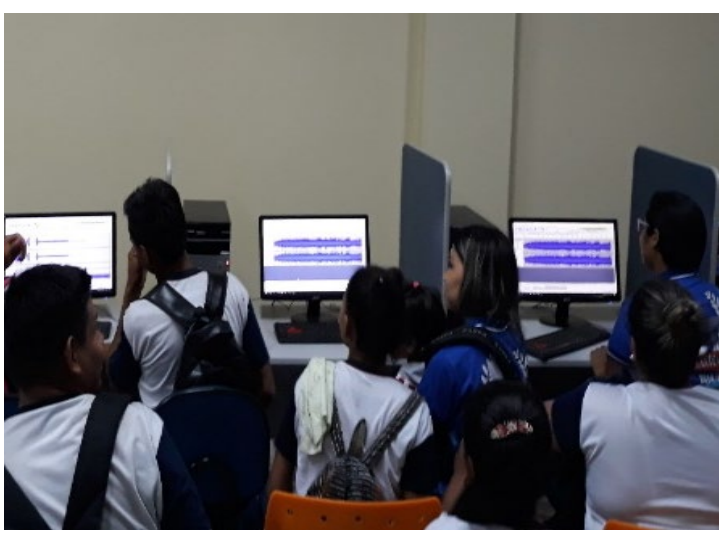

Fonte: Dados Primários, 2021.

Ao término da gravação das narrações, no laboratório de informática da escola, os alunos editaram os áudios digitais utilizando o software Audacity, esta atividade é mostrada na Figura 3, finalizando os arquivos de áudios em formato MP3.

A Culminância do Projeto finalizou o ciclo pedagógico e foi realizada em sala de aula. Os alunos apresentaram os resultados da pesquisa sobre a Constituição Brasileira e a ocupação da Amazônia em forma de áudios digitais editados. Nesta culminância, os alunos ouviram os trabalhos realizados por cada grupo e avaliação da intervenção com a aplicação do questionário estruturado. $O$ material produzido foi depositado no Laboratório de Informática.

Para a avaliação do Estudo de Caso, foi aplicado um instrumento avaliativo em forma de questionário impresso, com o objetivo de valorar os conhecimentos adquiridos pelos alunos e a sua percepção quanto à proposta pedagógica. Vale ressaltar que todos os alunos $(\mathrm{N}=26)$ responderam o questionário.

Quanto ao uso do software, foi questionado: Como foi a utilização do software Audacity na edição e produção dos áudios digitais? $\mathrm{E}$ os resultados foram transcritos para a Tabela 3.

Tabela 3 - Quanto ao uso do software Audacity ( $\mathrm{N}=26)$

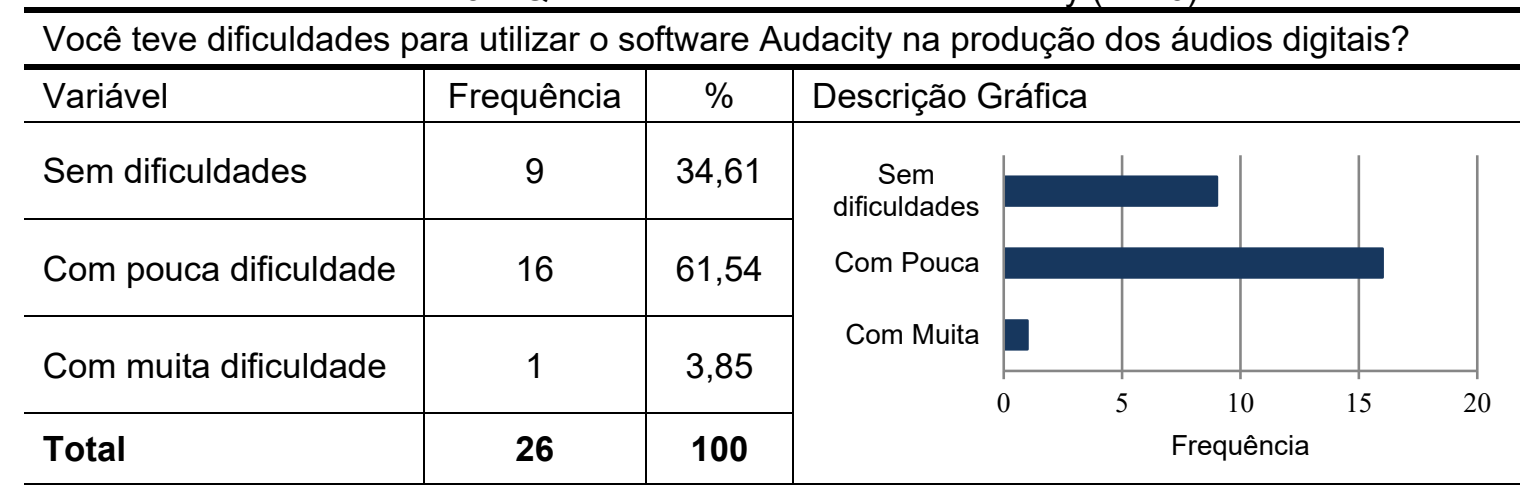

Fonte: Dados Primários, 2021. 
Nesse caso, apesar dos alunos não conhecerem o software Audacity e maioria ter afirmado que seu conhecimento em informática era limitado $(57,7 \%)$, constatou-se que todos $(100 \%)$ conseguiram desenvolver as atividades.

Percebe-se que a utilização das TIC como ferramenta pedagógica para os alunos da EJA, estimulam a leitura e o exercício da escrita, superando as dificuldades impostas falta de hábito de estudar, de ler, de compreender os conteúdos descritos por Santos (2015), ajudando a superar as dificuldades descritas, facilitando assim a aprendizagem destes alunos.

Para tanto, Porto (2018) ressalta que estas atividades devem ser sempre bem planejadas, analisadas e adaptadas para a realidade local, para potencializar o seu aproveitamento.

Outro ponto que foi questionado foi: a produção e edição dos áudios digitais no software Audacity favoreceram o seu aprendizado do conteúdo de História? 80,78\% afirmaram que SIM; 15,38\% disseram que favoreceu POUCO; e apenas 3,85\% disseram que NÃO favoreceu em nada o seu aprendizado na disciplina, conforme Tabela 4.

Tabela 4 - Quanto ao Aprendizagem sob a percepção do aluno ( $N=26)$

\begin{tabular}{l|c|c|r|r|r}
\hline Na sua opinião, a produção de áudios, favoreceu o seu aprendizado em História? \\
\hline Variável & Frequência & $\%$ & Descrição Gráfica & \\
\hline SIM & 21 & 80,78 & SIM & & \\
\hline POUCO & 4 & 15,38 & POUco & \\
\hline NÃO & 1 & 3,85 & NÃO & F \\
\hline Total & $\mathbf{2 6}$ & $\mathbf{1 0 0}$ & & 0 & Frequência \\
\hline
\end{tabular}

Fonte: Dados Primários, 2019.

A utilização de TIC já faz parte do cotidiano dos nossos alunos e estes recursos potencializam os processos educacionais abrindo novas possibilidade ao complemento de aula e práticas desta natureza para Torres e Irala (2014) empoderam digitalmente este público, podendo iniciar um processo transformador na realidade dos estudantes da EJA, abrindo novos horizontes e perspectivas no processo de ensino e aprendizado.

Outros trabalhos que endossam as perspectiva desta são os estudos de Sossai e Mendes (2016), que realizaram uma análise das narrativas orais sobre o uso de tecnologias digitais nas escolas públicas em Santa Catarina. Silveira (2017) utilizou o software Audacity como uma ferramenta para a gravação e edição do programa da Rádio Escolar, nesta mesma proposta Vieira (2018) utilizou o podcast e a leitura oralizada como forma de recurso para o envolvimento dos alunos do Ensino Médio nas aulas de literatura e por fim Saidelles, et al. (2019), investigaram as potencialidades do uso do Software Audacity como Ferramenta de Flexibilização da Aprendizagem.

Em análise qualitativa, a partir dos relatos dos alunos e corroborando com os resultados de Rios (2018) e Santos et al. (2019), constatou-se que, os participantes, ficaram realmente empolgados, motivados e participativos das atividades 
propostas, mesmo com certa dificuldade de manuseio do computador e no uso da ferramenta (VIEIRA; CRUZ, 2019).

\section{Conclusão}

Constatamos que inserir as TIC no ensino ainda é uma barreira a ser superada, tanto na parte humana quanto na infraestrutura dos ambientes escolares. Para tanto, neste Estudo de Caso, o uso delas com a finalidade pedagógica, em especial com o uso do software Audacity foi exitosa, trazendo resultados positivos no processo de ensino e aprendizagem, proporcionando condições favoráveis e motivadoras para os alunos da EJA. Este estudo não pretendeu esgotar as discussões acerca da utilização das TIC como ferramentas de ensino, mas confirmá-la como um suporte repleto de possibilidades para o enriquecimento das propostas pedagógicas. Outro resultado positivo constatado neste estudo foi que a criação de mecanismos criativos motivou a interação dos alunos com novas ferramentas de aprendizagens. Assim, o uso software Audacity contribuiu de forma positiva e significativo para o ensino e aprendizagem do conteúdo de História para os alunos da EJA de uma escola da rede pública de ensino da cidade de CoariAmazonas-Brasil.

\section{Referências}

ALMEIDA, Lígia Beatriz Carvalho de; MENDES, lasmin Araújo Bandeira; LIMA, Maria do Socorro Nunes de; Gustavo de Souza SILVA, Programa De Extensão "Mídias Na Educação": Estimulando A Formação De Leitores Paraibanos. Revista UFG, $\quad$ v. $18, \quad$ n. $24,2018 . \quad$ Disponível em: https://www.revistas.ufg.br/revistaufg/article/view/58617. Acesso em: 03 fev. 2020.

ALMEIDA, Maria Elizabeth Bianconcini de. Tecnologias na Educação: dos caminhos trilhados aos atuais desafios. Bolema-Boletim de Educação Matemática, v. 21, n. 29, p. 99-129, 2008. Disponível em: https://www.redalyc.org/pdf/2912/291221870006.pdf. Acesso em: 14 jan. 2020.

ANDELIERI, Sônia; ADÓ, Máximo Daniel Lamela. Tecnologia, educação e práticas na EJA, In: (Org.) STECANELA, Nilda; AGLIARDI, Delcio Antônio; LORENSATTI, Edi Jussara Candido. Ler e Escrever o Mundo: a EJA no contexto da educação contemporânea. Caxias do Sul, RS: Editora EDUCS, p. 239 - 252, 2014.

ANDRADE, Maria Margarida de. Introdução à metodologia do trabalho científico: elaboração de trabalhos na graduação. 10. ed. São Paulo: Atlas, 2018.

BOCASANTA, Daiane Martins; WISCH, Tasia. "Daqui uns tempos é tudo informática": análise de uma experiência nos Anos Iniciais da EJA. Cadernos do Aplicação, v. 31, n. 2, p. 10-19, 2018. Disponível em: https://www.seer.ufrgs.br/CadernosdoAplicacao/article/view/89532. Acesso em: 11 jan. 2020.

BRAGA, Paulo Roberto. Sequências didáticas e tecnologias digitais: propostas para o trabalho com a Geografia no Ensino Fundamental. 2019. 125f. Monografia (Especialização Tecnologias Digitais e Educação 3.0) Escola de Educação Básica e Profissional da Universidade Federal de Minas Gerais, Belo Horizonte, 2019.

4


BRASIL. Exame Nacional para Certificação de Competências de Jovens e Adultos - Encceja 2018. Instituto Nacional de Estudos e Pesquisas Educacionais. 2018. Brasília, 2018.

BRASIL. Lei n. 9.394, de 20 de dezembro de 1996. Lei de Diretrizes e Bases da Educação Nacional. Brasília, DF, 1996.

CARVALHO, Luana Rocha da Silva. Uma reflexão sobre o ensino-aprendizagem da EJA: perspectivas didáticas, uso das Tic's e recursos pedagógicos. 2016. 29f. Monografia (Licenciatura em Pedagogia) Universidade Federal do Rio Grande do Norte, Natal-RN, 2016.

COELHO, Lívia Andrade. As relações dos alunos da EJA com as tecnologias digitais: implicações e possibilidades na vida de cada um. 2011. $138 f$. Dissertação (Mestrado em Educação) Universidade Federal da Bahia, Salvador, 2011.

COOPER, Donald R.; SCHINDLER, Pamela S. Métodos de pesquisa em administração. 12. ed. Porto Alegre: AMGH, 2016.

COSTA, Maria Adélia; MENESES, Rejane Cassiano. O Uso das Tecnologias na Formação Docente de Nível Médio: O Curso Normal. Formação@ Docente, v. 11, n. 1, p. 95-111, 2019. Disponível em: https://www.metodista.br/revistasizabela/index.php/fdc/article/view/1747. Acesso em: 14 jan. 2020.

DIAS, Fernanda Aparecida Silva; DIAS, João Valdir. O Uso das Tecnologias Digitais nas Aprendizagens de Jovens e Adultos. Redin-Revista Educacional Interdisciplinar, v. 7 , n. 1, p. 1-19 2018. Disponível em: http://seer.faccat.br/index.php/redin/article/view/1101. Acesso em: 03 fev. 2020.

FERRARETTO, Luiz Artur. Rádio: teoria e prática. 1. Ed. São Paulo: Summus, 2014.

FLORES, Álvaro Dall Molin; RIBEIRO, Luciano Maciel; ECHEVERRIA, Evandro Luiz. A tecnologia da informação e comunicação no ensino superior: Um olhar sobre a prática docente. Revista Espacios, v. 38, n. 5, p. 17-31, 2017. Disponível em: http://www.revistaespacios.com/a17v38n05/a17v38n05p17.pdf. Acesso em: 30 jan. 2020.

FREIRE, Paulo. Educação e Mudança. São Paulo: Paz e Terra, 1979.

GIL, Antônio Carlos. Como elaborar projetos de pesquisa. 6. ed. São Paulo: Atlas, 2018.

GIOVANI, F. N.B. SOUZA, C. L. PERALTA, L.P.F. MOREIRA, L.B. SILVA, F. C. GRANATO, A. CORTEZ, A. G. D'AVILA, T.P. BARBOSA, M.E.M. SANTOS, B.V. ABOTT, E. S. ROSA, R.V. SOARES. A rádio escolar como veículo de vozes sociais: os desafios e possibilidades da implantação de um projeto. Articulações universidade-escola: a construção de sentidos na/para ação docente. Itajaí: Casa Aberta, p. 337-354, 2014. Disponível em: https://periodicos.unipampa.edu.br/index.php/SIEPE/article/view/87051. Acesso em: 10 fev. 2020.

GOMES, Josibias Ferreira. Educação de Jovens e Adultos (EJA): Análise da motivação para permanência na EJA dos discentes da Escola Ministro José Américo de Almeida. 2017. 45f. Monografia (Graduação em Pedagogia), Universidade Federal da Paraíba, João Pessoa, 2017. 
LOPES, Rita de Cássia Soares. A relação professor, aluno e o processo ensino aprendizagem. Obtido a, v. 9, n.1, p. 1-28, 2011. Disponível em: http://www.diaadiaeducacao.pr.gov.br/portals/pde/arquivos/1534-8.pdf. Acesso em: 10 fev. 2020.

MALHOTRA, Naresh K. Pesquisa de marketing: uma orientação aplicada. 7. ed. Porto Alegre: Bookman, 2019.

MARQUES, Luiz Felipe; STENTZLER, Márcia Marlene. Oficinas Pedagógicas no Ensino de História e Cultura Afro-Brasileira: Contribuições a Partir do PIBID. eMosaicos, v. 8, n. 19, p. 189-203, 2019. Disponível em: https://www.epublicacoes.uerj.br/index.php/e-mosaicos/article/view/46577. Acesso em: 18 jan. 2020.

NOGUEIRA, Nilbo Ribeiro. Práticas pedagógicas e uso da tecnologia na escola. 1. ed. Rio de Janeiro: Érica, 2014.

NUNES, Elizabeth Lobato; DIAS, Jacirema de Jesus Fernandes; LIMA, Rafael Pontes. Letramento digital: estudo de caso sobre a formação para o conhecimento de informática através do curso UNIFAPDIGITAL. PRACS: Revista Eletrônica de Humanidades do Curso de Ciências Sociais da UNIFAP, v. 8, n. 2, p. 119-136, 2016. Disponível em: https://periodicos.unifap.br/index.php/pracs/article/view/1875. Acesso em: 22 jan. 2020.

PESCADOR, Cristina Maria. Ações de aprendizagem empregadas pelo nativo digital para interagir em redes hiper midiáticas tendo o inglês como língua franca. 2010. 142 f. Dissertação (Mestrado em Educação) Programa de PósGraduação em Educação. Universidade de Caxias do Sul, Caxias do Sul, 2010.

PORTO, Caroline dos Santos. Edmond: o uso da rede social educativa no desenvolvimento de uma atividade com alunos do EJA. 2018. 24f. Monografia (Especialização em Tecnologias da Informação e da Comunicação Aplicadas à Educação) - Universidade Federal de Santa Maria, Santa Maria, RS, 2018.

RIOS, Erika Carolina dos Santos Vieira. A INSERÇÃO DA INFORMÁTICA NA EJA. Conhecimento em Destaque, v. 3, n. 7, p. 1-19, 2018. Disponível em: http://ead.soufabra.com.br/revista/index.php/cedfabra/article/viewFile/92/96.

Acesso em: 22 jan. 2020.

RIOS, Rejane Risia Gonçalves. A importância das TDIC'S para o desenvolvimento do processo ensino - aprendizagem na educação de jovens e adultos EJA. Revista Internacional de apoyo a la inclusión, logopedia, sociedad y multiculturalidad, v.2, n.3, p. 212-220, 2016. Disponível em: https://revistaselectronicas.ujaen.es/index.php/riai/article/view/4230. Acesso em: 2 fev. 2020.

ROSA, Harlei Vasconcelos. Tecnologias digitais e educação: os dispositivos móveis nas políticas públicas de inserção das tecnologias na escola. 2017. $236 \mathrm{f}$. Tese (doutorado) - Universidade Federal da Bahia. Faculdade de Educação, Salvador, 2017.

SAID Anna Christina Castro Corrêa; PEREIRA, Gleice; GONÇALEZ, Paula Regina Ventura Amorim; GUIMARAES, Rachel Cristina Mello. As Tecnologias de Informação e Comunicação como Mediadoras nas Práticas Pedagógicas da EJA para Jovens e Adultos. In: CONGRESSO BRASILEIRO DE BIBLIOTECONOMIA E DOCUMENTAÇÃO, XXVIII, Vitória, 2019. In: Anais do Congresso Brasileiro de

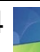


Biblioteconomia, Documentação e Ciência da Informação-FEBAB. Vitória, p. 16, 2019. Disponível em: https://portal.febab.org.br/anais/article/view/2153. Acesso em: 14 fev. 2020.

SAIDELLES, Tiago; SCHMITT, Janaína de Arruda Carilo; BARIN, Cláudia Smaniotto; ELLENSOHN, Ricardo Machado; SANTOS, Leila Maria Araújo. Investigando as Potencialidades do Uso do Software Audacity como Ferramenta de Flexibilização da Aprendizagem. Redin-Revista Educacional Interdisciplinar, v. $8, \quad$ n. $1, \quad$ p. $1-9, \quad 2019 . \quad$ Disponível em: http://seer.faccat.br/index.php/redin/article/view/1543. Acesso em: 27 fev. 2020.

SAMPAIO, Rosa Nunes. 0 rádio na EJA - Educação de Jovens e Adultosutilizando o programa Audacity na web como recurso técnico para a gravação do áudio. 2015, 18f. Monografia (Especialização em Mídias Integradas na Educação), Universidade Federal do Paraná, Curitiba, 2015.

SANTOS, Dayanna Pereira dos; SOUZA, Nelson Miguel de. Um estudo sobre o uso das TIC e a química na educação de jovens e adultos (EJA). Brazilian Journal of Development, v. 4, n. 7, p. 4128-4146, 2018. Disponível em: https://www.brazilianjournals.com/index.php/BRJD/article/view/481. Acesso em: 03 fev. 2020.

SANTOS, Débora Regina Oliveira; AMORIM, Antônio; DA MATTA, Alfredo Eurico. Experiências de Formação Docente em EJA por meio do Uso das Tecnologias da Informação e Comunicação. Cadernos de Pesquisa, v. 24, n. 3, p. 127-140, 2017. Disponível

em: http://www.periodicoseletronicos.ufma.br/index.php/cadernosdepesquisa/article/vie w/8030. Acesso em: 27 jan. 2020.

SANTOS, Juliana Rodrigues dos; SILVA, Jean Michel da; LOZZA, Silvia Luan; SILVA, Rodrigo Ribeiro da. Jogo Como Ferramenta Pedagógica no Processo de Aprendizagem de Jovens e Adultos com Dificuldades. Caderno PAIC, v. 20, n. 1, p. 461-476, 2019. Disponível em: https://cadernopaic.fae.emnuvens.com.br/cadernopaic/article/view/385.Acesso em: 25 jan. 2020.

SANTOS, Maria Inêz Frozza Borges dos. As Causas das dificuldades de ensino e aprendizagem na EJA e as contribuições da psicopedagogia, 2015. 20f. Monografia (Especialização em Educação Profissional integrada à Educação Básica na Modalidade PROEJA) Instituto Federal de Santa Catarina, Santa Catarina, 2015.

SILVEIRA, Rita De Cássia Angeieski da. UO letramento do professor para a mediação no processo de desenvolvimento da rádio escolar. 2017. $127 f$. Dissertação (Mestrado Profissional em Ensino de Línguas) - Universidade Federal do Pampa, Campus Bagé, Bagé, 2017.

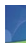


SOSSAI, Fernando Cesar; MENDES, Geovana Mendonça Lunardi. Tempo tecnológico: uma análise de narrativas orais sobre o uso de tecnologias digitais em escolas públicas de Santa Catarina. História Oral, v. 19, n. 1, p. 7-39, 2016. Disponível em: http://revista.historiaoral.org.br/index.php?journal=rho\&page=article\&op=view\&pat h\%5B\%5D=628\&path\%5B\%5D=pdf. Acesso em: 20 jan. 2020.

TELES, Damares Araújo; SOARES, Maria Perpétua do Socorro Beserra. Educação de jovens e adultos: desafios e possibilidades na alfabetização. Revista Educação e Emancipação, v. 9, n.1, p. 80-102, 2016. Disponível em: http://www.periodicoseletronicos.ufma.br/index.php/reducacaoemancipacao/article/ view/4980. Acesso em: 29 jan. 2020.

TORRES, Patrícia Lupion; IRALA, Esrom Adriano Freitas. Aprendizagem colaborativa: teoria e prática. In: TORRES, P. L. (Org.). Complexidade: redes e conexões na produção do conhecimento. Curitiba: Senar-PR, v.1, p. 61-93, 2014.

VIEIRA, Maria Clarisse; CRUZ, Karla Nascimento. A Produção Sobre o Uso das Tecnologias Digitais da Informação e Comunicação na Educação de Jovens e Adultos. Educação em Foco, v. 22, n. 36, p. 58-74, 2019. Disponível em: https://revista.uemg.br/index.php/educacaoemfoco/article/view/2723. Acesso em: 5 fev. 2020.

VIEIRA, Michele Lago Machado. O podcast e a leitura oralizada como recurso para o envolvimento de alunos do ensino médio nas aulas de literatura. 2018, 85f. Dissertação (Mestrado Profissional em Ensino de Línguas) Universidade Federal do Pampa, Campus Bagé, Bagé, 2018.

VILLAÇA, Leonardo Drummond; LIMA, Regina Célia Vilhaça. Oficina de Educomounicação: Comunicação e Mídias na Escola. Vol. 3. São Paulo: Rideel, 2015.

Recebido: $28 / 03 / 2020$

Aprovado:.09/02/2021

Como citar: YAMAGUCHI, H. K. L; BARRETO, W. M. O uso do Software Audacity como Mediação Pedagógica no Ensino de História para Educação de Jovens e Adultos. Revista de Estudos e Pesquisas sobre Ensino Tecnológico (EDUCITEC), v. 7, e123621, 2021.

Direito autoral: Este artigo está licenciado sob os termos da Licença Creative CommonsAtribuição 4.0 Internacional. 